\title{
SOME INSTANCES OF UNSTABLE SURFACE TEMPERATURE CONDITIONS DURING AN ARCTIC WINTER*
}

\author{
Elmer Robinson $\dagger$
}

\begin{abstract}
$\mathbf{A}^{\mathrm{T}}$
TMOSPHERIC conditions in which the air has a vertical temperature stratification such that portions tend to rise and become turbulent, are frequently observed in temperate climates. These turbulent conditions, in which the atmosphere is said to have an unstable or superadiabatic temperature gradient are commonly caused by solar heating of the earth's surface and the transfer of some of the earth's heat to the atmosphere. Such conditions produce the vertical transport of moisture evidenced by cumulus clouds.

Although the Arctic is generally characterized by a stable or quiescent atmospheric structure, unstable conditions ${ }^{1}$ as shown by superadiabatic temperature gradients do occur. They were recorded during a field observational program at Eielson Air Force Base, near Fairbanks, Alaska. The fact that these conditions were observed in winter when the sun was at a very low angle above the horizon, and even on overcast days, led to a more detailed examination of the data to explain the cause of these phenomena. Although these turbulent or superadiabatic situations are much less frequent during the arctic winter than are inversions or stable conditions, they appear to be important in some arctic weather situations, of which ice fog is one example. Data on the occurrence of unstable surface temperature gradients will thus aid the description of various aspects of the weather in the Arctic and will show some of the complexities of northern weather.

Superadiabatic lapse rates were observed under several different general weather conditions. One, as might be expected, was during periods of strong insolation when the snow surface was in bright sun. Although the sun is quite low during much of the winter in the Fairbanks area, surface heating at about noon begins to be significant after the middle of February. Another condition which was observed to cause a superadiabatic situation was one in which a heavy overcast and an overriding air mass considerably warmer than

*This study represents a portion of a project dealing with Alaskan ice fog and supported by U.S. Air Force Cambridge Research Center under Contract No. AF19(122) - 634 .

†Stanford Research Institute, California.

1An unstable condition is one in which the air temperature decreases with increasing height at more than $1^{\circ} \mathrm{C}$ per $100 \mathrm{~m}$. This unstable condition is also called superadiabatic because the rate of temperature change is greater than what would take place in a vertically moving air parcel under adiabatic conditions. An unstable condition favours the vertical movement of air parcels.
\end{abstract}


Fig. I.

Meteorological tower instrumentation, Eielson Air Force Base, Alaska, 1954.

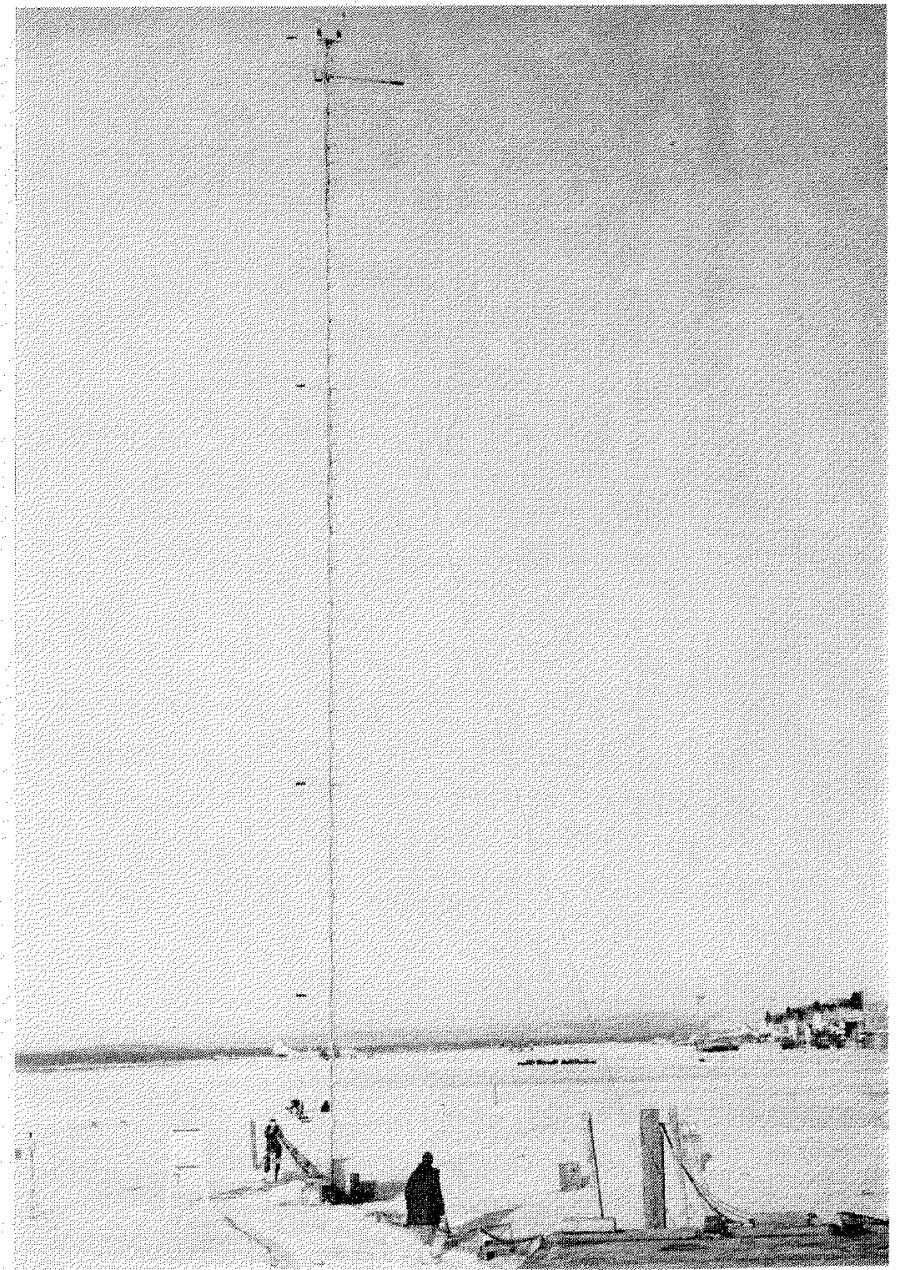

the surface was present over the area. In this case it seems apparent that the warmer air mass aloft supplied the radiant energy which supported the superadiabatic lapse rate at the surface. A third type of surface instability occurred during a large number of ice fog situations. This was apparently due to the "greenhouse" effect of the fog layer and thus was similar to the instability due to the overriding warm air mass.

\section{Equipment}

Observations of the atmospheric temperature structure were made using a tower equipped for recording the routine micrometeorological variables. This equipment has been described previously (Wiggins and others, 1954, pp. 99-102) but a brief description is warranted in the present discussion.

Figure 1 shows the tower and levels at which the various observations were made. The essential components of the recording system for the determinations of temperature gradients were copper-constantan thermo- 
couples, a thermostated reference junction, a Weston "Inductronic" DC amplifier, and a multipoint Brown recording potentiometer. The thermocouples (except for the snow-surface thermocouple, which was unprotected) were shielded with sheets of polished aluminum patterned after Thornthwaite (1949, pp. 6-7). The data from the tower instruments related to the study of temperature gradients are:

1. Air temperature at $2 \mathrm{~m}$.

2. Air temperature at $29 \mathrm{~m}$.

3. Temperature difference between snow surface and $2 \mathrm{~m}$.

4. Temperature difference between $5 \mathrm{~m}$. and $2 \mathrm{~m}$.

5. Temperature difference between $10 \mathrm{~m}$. and $2 \mathrm{~m}$.

6. Temperature difference between $20 \mathrm{~m}$. and $2 \mathrm{~m}$.

7. Temperature difference between $29 \mathrm{~m}$. and $2 \mathrm{~m}$.

The air temperatures were recorded directly by the Brown recorder, using the reference junction thermostated at $0^{\circ} \mathrm{C}$. The temperature differences were amplified by the Weston amplifier before being recorded. Since

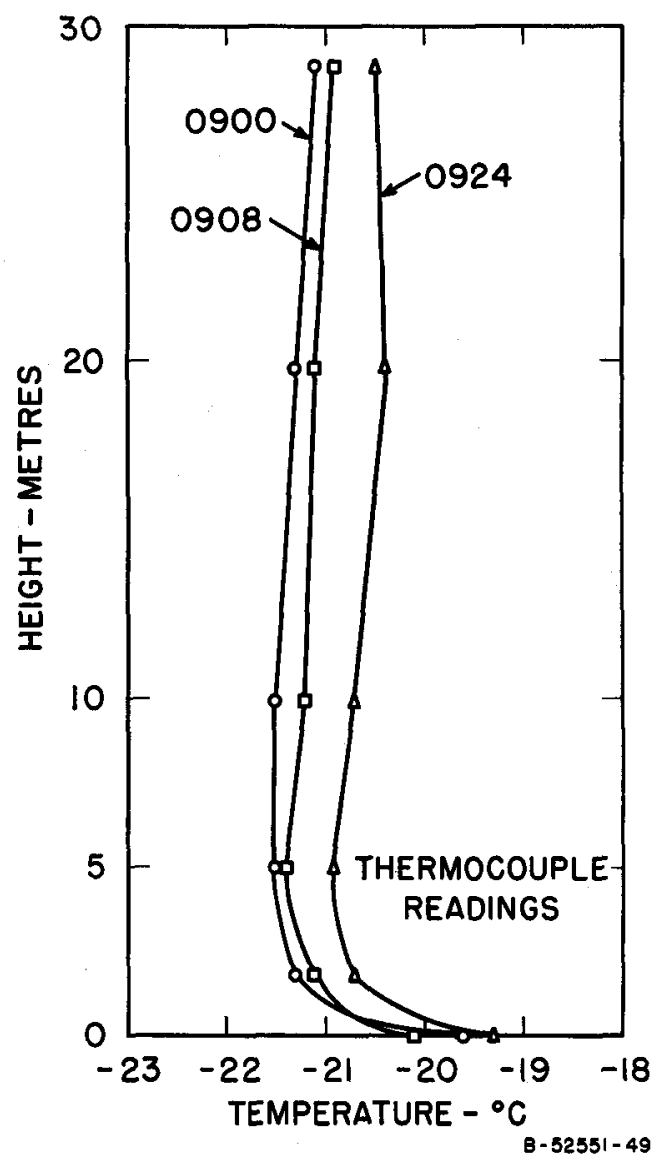

Fig. 2. Superadiabatic profiles, Eielson Air Force Base, 18 January 1954. 


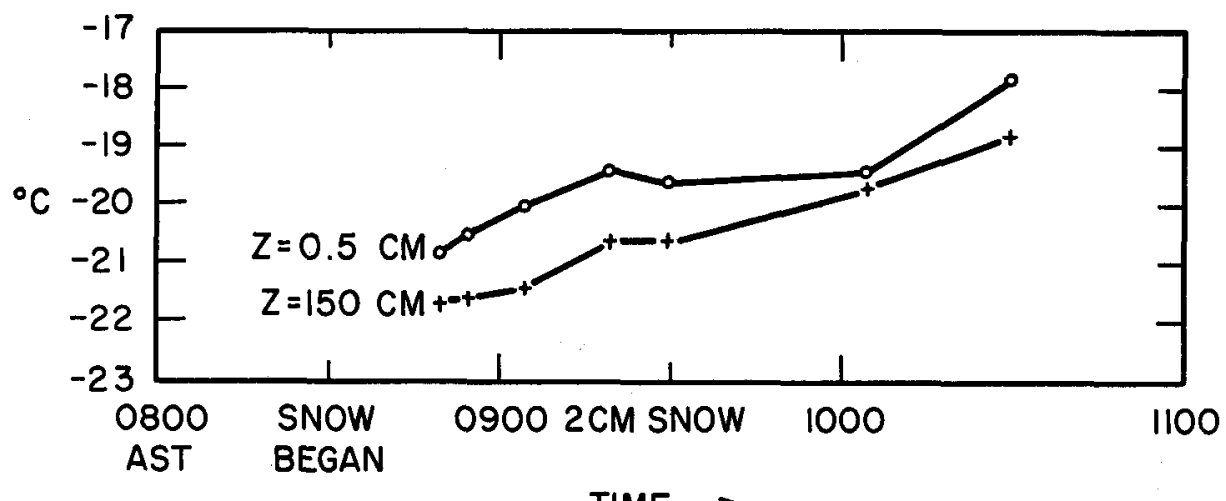

\section{TIME $\rightarrow$}

Fig. 3. Air temperatures from two thermometers, Eielson Air Force Base, 19 January 1954.

the snow was often at least $25 \mathrm{~cm}$. deep, the distance between the surface thermocouple and the thermocouple at the $2-\mathrm{m}$. tower level was generally less than $2 \mathrm{~m}$.

\section{Observations under overcast conditions}

On 18 January 1954 it was possible to make some special studies of an unstable situation that occurred with a heavy overcast and an overriding warm air mass. This situation lasted for at least 8 hours, with a moderate-toheavy snowfall (for the Fairbanks area) during the last few hours and temperatures around $-20^{\circ} \mathrm{C}$.

Figure 2 shows the profiles through the first $29 \mathrm{~m}$. as recorded by the micrometeorological equipment at 0900, 0908, and 0924 hours, local time, under heavy overcast from which snow was falling. The data show an unstable or superadiabatic condition to a height of $5 \mathrm{~m}$., above which there was a weak inversion. Winds, during this half-hour period, were about $1 \mathrm{~m}$. .h. and about $1 \mathrm{~cm}$. of very light fluffy snow accumulated while the measurements were being made. Total snow cover was about $20 \mathrm{~cm}$. These observations are typical of the period during which the unstable conditions lasted.

This unstable condition was also studied with alcohol thermometers. Two thermometers (Cenco No. 19360 , calibrated from $0^{\circ}$ to $-50^{\circ} \mathrm{C}$ in $0.2^{\circ} \mathrm{C}$ divisions) which had been checked and found to indicate the same temperature when hanging side by side in the open air, were used. One was placed next to the surface thermocouple with its bulb at the level of the thermocouple, about $1 / 2 \mathrm{~cm}$. above the snow surface. The other thermometer was hung from the shield of the $2-\mathrm{m}$. thermocouple. The thermometer bulbs were $150 \mathrm{~cm}$. apart and the thermocouples were $175 \mathrm{~cm}$. apart. The readings of these two thermometers at various times between 0850 and 1030 hours are shown in Fig. 3. Temperatures rose by $3^{\circ} \mathrm{C}$ at both heights between the first observation at 0850 and the last at 1030 . The maximum difference $1.4^{\circ} \mathrm{C}$ 


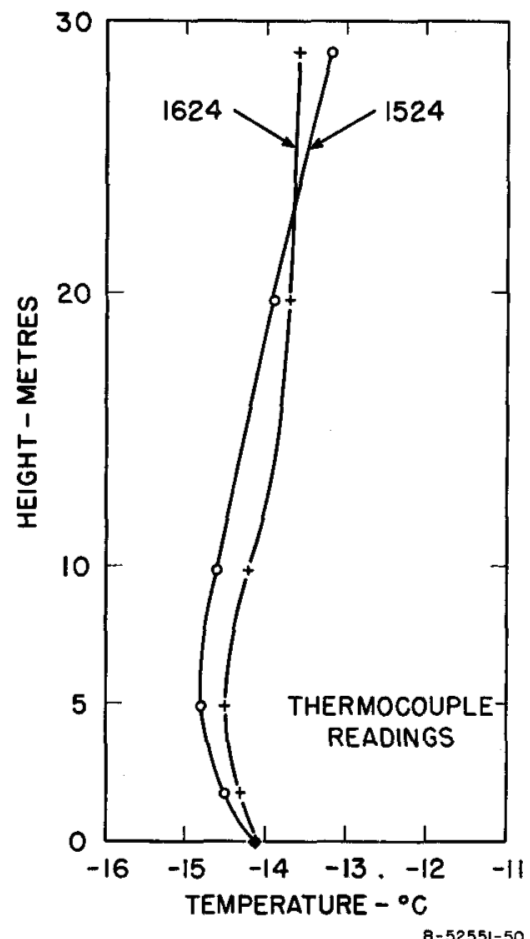

Fig. 4. Superadiabatic profiles, Eielson Air Force Base, 19 January 1954.

was recorded by the thermocouples at 0905 and is similar to the $1.6^{\circ} \mathrm{C}$ difference recorded by the thermocouples.

The heavy overcast conditions changed little during the rest of January 18 and persisted through the following day. Fig. 4 shows the conditions on January 19 at 1524 and 1624 hours. The surface lapse conditions up to a height of $5 \mathrm{~m}$. were not as strong as on the previous day and the temperatures at all levels had risen several degrees. The inversion above $5 \mathrm{~m}$. was steeper.

To maintain this observed superadiabatic surface layer the surface had to be receiving energy from some source, and it seems evident that during these two days the source was the warm cloud layers aloft. The temperatures in these cloud layers, as recorded by the Fairbanks Weather Bureau upper air observations for 0500 on January 18 and 19, are shown in Fig. 5. On the 18th the warmest air $\left(-5^{\circ} \mathrm{C}\right)$ was found at around $1,500 \mathrm{~m}$. whereas on the 19th the warmest layer $\left(-11^{\circ} \mathrm{C}\right)$ was at around $300 \mathrm{~m}$. These upper air temperatures at Fairbanks are the only ones available for this period but were probably fairly representative of the conditions over the laboratory at Eielson AFB, 30 miles away and several hours later in the day. Even though the surface temperatures varied by a number of degrees the upper level conditions would not be expected to show similar variations.

As Fig. 1 shows, the tower was equipped to record the net radiation at heights of 2 and $29 \mathrm{~m}$. During the observation period on January 18 , the net radiation was measured as incoming from 166 to $332 \times 10^{-6} \mathrm{cal} . / \mathrm{cm} .{ }^{2} / \mathrm{sec}$. at 
the 2-m. level. These data substantiate the explanation that the unstable conditions were due to incoming radiation at a time when, because of the heavy overcast, the warmer cloud layers were the only apparent source of radiation.

\section{Observations under diurnal insolation conditions}

Unstable conditions due to insolation on the surface could be observed on almost any clear day at Eielson AFB after early February. Fig. 6 shows a typical progression from inversion or stable to unstable and back to inversion conditions as a result of the diurnal insolation cycle. These data are hourly average temperatures recorded at the tower installation on 19 February 1954. The 0600 hours data, average values for the period 0530 to 0630 , show a $1.5^{\circ} \mathrm{C}$ increase or inversion in the first $2 \mathrm{~m}$., near isothermal conditions between the 2 and $10-\mathrm{m}$. levels, and a stronger inversion in the levels between 10 and $29 \mathrm{~m}$. The isothermal level was doubtless associated with the presence of a shallow ice fog during this period. This type of profile was fairly typical of a shallow fog. By 0900 a very weak superadiabatic layer was evident in the lowest $2 \mathrm{~m}$., although there was only a $-0.5^{\circ} \mathrm{C}$ change in temperature. During the period 0830 to 0930 hours, which was averaged for the 0900 data, the ice fog had disappeared along with most of the stability which characterized the surface to $28-\mathrm{m}$. air layer during the 0600 period. The average data show that by 1200 hours a more unstable surface condition had developed, temperatures were almost $15^{\circ} \mathrm{C}$ warmer than those recorded at 0600 , and considerable warming had occurred at all levels. The reason for the "sand-

Fig. 5. Radiosonde observations,

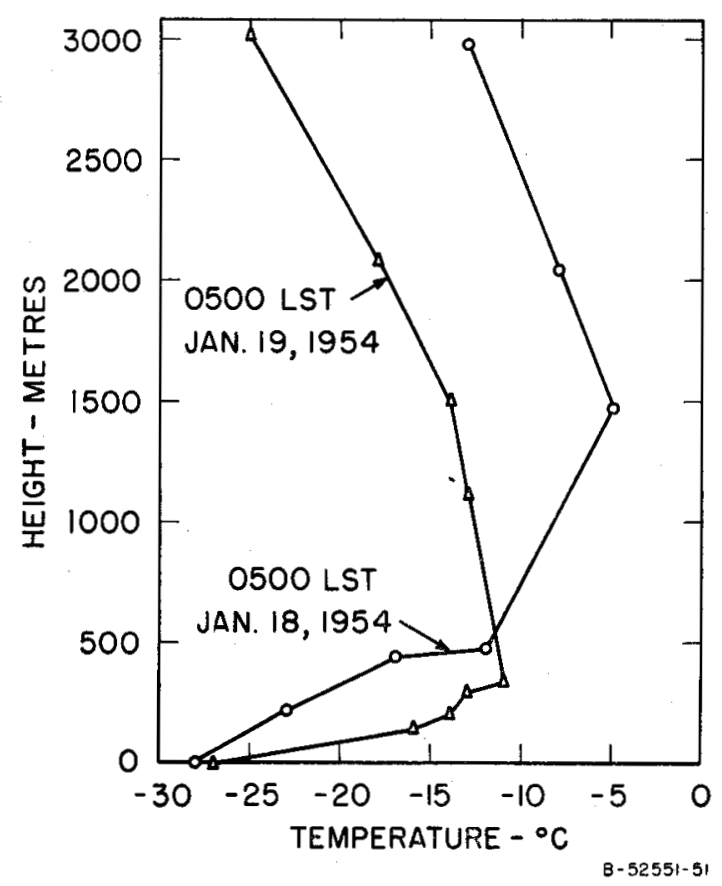

Fairbanks, Alaska. 


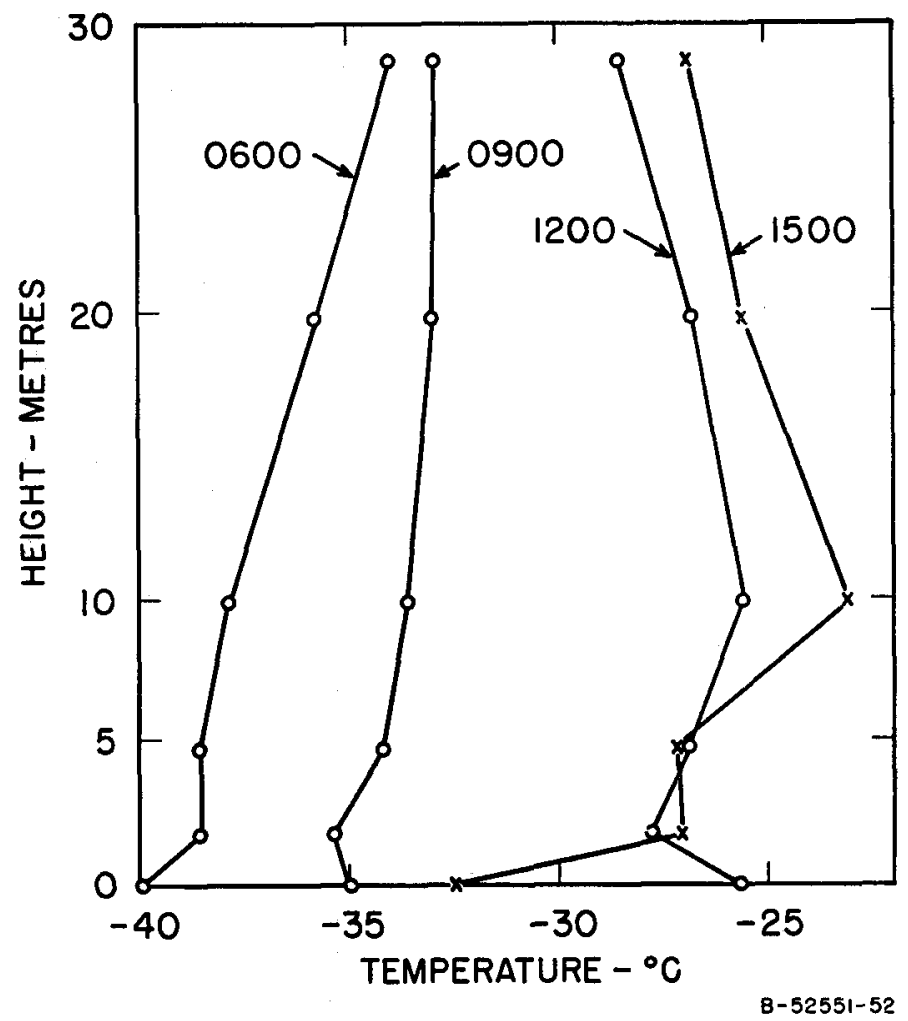

Fig. 6.

The development of unstable conditions through insolation, Eielson Air Force Base, 19 February 1954.

wich" type of profile (the inversion bounded by two unstable layers) is not clear. However, a review of the data indicated that it was a recurrent feature and not a transitory situation. By 1500 hours the lowest level again showed an inversion which was over $5^{\circ} \mathrm{C}$ in magnitude. An unstable condition, which seemed to be a remnant of the earlier condition, was maintained between 10 and $29 \mathrm{~m}$. The cycle continued in a more or less regular manner during the remainder of the day, with increasing stability in the surface layers.

Net radiation measurements during this period of insolation indicated a maximum of incoming radiation between 1100 and 1200 hours and maximum of outgoing radiation between 1400 and 1500 hours, after which it gradually decreased through the rest of the afternoon and evening. This pattern of radiation was frequently observed; it seems to have been caused by the following sequence of events. First, the period of positive, net incoming radiation around noon was a result of direct insolation. This positive radiation not only warmed the surface, but promoted the clearing of the atmosphere of smoke and fine particles through thermal turbulence, as is shown by the unstable or superadiabatic conditions, and by thermally-induced local winds. The second phase, the rapid radiation loss by the surface, occurred with a decrease in the insolation in the early afternoon and was facilitated by the clear atmosphere. The third phase of the radiation cycle, the decrease of the net outgoing radiation, occurred as the surface radiational inversion 
became re-established and was accompanied by a gradual accumulation of smoke and particulates. This produced an atmosphere less transparent to radiation from the surface and in severe cases, such as ice fog, the surface radiation was interrupted so much that the surface inversion was again destroyed.

\section{Observations during ice fog}

The data for 0600 in Fig. 6 show the tendency toward instability during ice fog. This type of profile is caused by the absorption and re-radiating characteristics of fog, which restrict the ground surface from acting as a radiating surface and, instead, the top of the fog layer becomes the principal radiator. This tends to produce lapse conditions in the levels beneath the top of a fog and a steeper inversion above fog (Fleagle and others, 1952). Since studies of ice fog have shown that it is almost exclusively confined to inhabited areas, this instability situation seems to be of minor importance with regard to arctic climatology in general, although it is of interest in the problem of ice fog itself and in the microclimate of urban areas in the Arctic.

\section{Seasonal conditions}

The frequencies at which various lapse rate conditions occurred in the surface to $2-\mathrm{m}$. and 2 to $5-\mathrm{m}$. levels are shown in Table 1 , taken from hourly average data taken between 1 January and 28 February, 1954. A summary

Table 1. Frequency combinations of temperature differences and air temperature at a height of 2 metres. Hourly average data for the period 1 January to 28 February 1954, Eielson Air Force Base, Alaska.

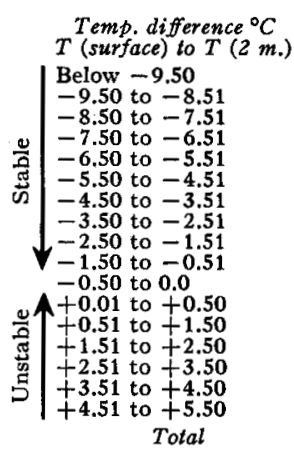

\begin{tabular}{|c|c|c|c|c|c|c|c|}
\hline \multirow{3}{*}{$\begin{array}{c}\text { Below } \\
-40\end{array}$} & \multicolumn{6}{|c|}{2 metre air temperature ${ }^{\circ} \mathrm{C}$} & \multirow[b]{2}{*}{ Total } \\
\hline & $\begin{array}{c}-40.0 \\
t o \\
-35.1\end{array}$ & $\begin{array}{c}-35.0 \\
t o \\
-30.1\end{array}$ & $\begin{array}{r}-30.0 \\
t 0 \\
-25.1\end{array}$ & $\begin{array}{r}-25.0 \\
t 0 \\
-20.1\end{array}$ & $\begin{array}{r}-20.0 \\
\text { to } \\
-15.1\end{array}$ & $\begin{array}{r}-15.0 \\
t o \\
-10.1\end{array}$ & \\
\hline & & & 8 & 4 & & & 12 \\
\hline & 1 & 3 & 6 & 7 & 1 & & 18 \\
\hline & & 14 & 14 & 7 & 2 & 1 & 38 \\
\hline & 5 & 12 & 15 & 2 & 4 & 2 & 40 \\
\hline & $\frac{11}{22}$ & 10 & 29 & 15 & 3 & 2 & 81 \\
\hline & 34 & 20 & 23 & 23 & 9 & 5 & 117 \\
\hline 10 & 38 & 11 & 26 & 36 & 16 & 17 & 154 \\
\hline 15 & 44 & 6 & 30 & 27 & 7 & 15 & 144 \\
\hline 9 & 38 & 10 & 33 & 13 & 19 & 26 & 148 \\
\hline 3 & 13 & 7 & 15 & 14 & 37 & 31 & 120 \\
\hline 1 & 8 & 4 & 23 & $\overline{7}$ & 27 & 18 & 88 \\
\hline 1 & 12 & 10 & $\begin{array}{r}24 \\
8\end{array}$ & 12 & 15 & $\begin{array}{r}31 \\
4\end{array}$ & 60 \\
\hline & 20 & 11 & 8 & 4 & 2. & & 30 \\
\hline & 1 & 2 & 4 & 1 & & $\begin{array}{l}1 \\
2\end{array}$ & $\begin{array}{l}9 \\
6\end{array}$ \\
\hline 42 & 243 & 145 & 288 & 215 & 196 & 160 & 1289 \\
\hline
\end{tabular}

Temp. difference $T(2 \mathrm{~m}$.$) to T(5 \mathrm{~m}$.

$$
\begin{aligned}
& \text { c) }-5.50 \text { to }-4.51
\end{aligned}
$$

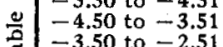

$$
\begin{aligned}
& -2.50 \text { to }-1.51 \\
& -1.50 \text { to }-0.51 \\
& -0.50 \text { to } 0.0 \\
& \begin{array}{l}
-0.50 \text { to } 0.0 \\
+0.01 \text { to }+0.50 \\
+0.51 \text { to }+1.50
\end{array} \\
& \text { 鸷 } \begin{array}{l}
+0.51 \text { to }+1.50 \\
+1.51 \text { to }+2.50
\end{array} \\
& \text { D Total }
\end{aligned}
$$

$\begin{array}{rr}2 & 11 \\ 3 & 15 \\ 3 & 45 \\ 10 & 59 \\ 3 & 47 \\ 7 & 27 \\ 13 & 45 \\ 1 & 3 \\ 42 & 252\end{array}$

$\begin{array}{ll}10 & \\ 25 & \\ 49 & 106 \\ 28 & 107 \\ 13 & \\ 21 & \\ 146 & 29\end{array}$

$\begin{array}{rr}3 & \\ 1 & 1 \\ 25 & 4 \\ 106 & 78 \\ 107 & 89 \\ 39 & 29 \\ 10 & 1 \\ 291 & 208\end{array}$

$\begin{array}{rr}1 & 2 \\ 3 & 1 \\ 6 & 3 \\ 40 & 26 \\ 82 & 85 \\ 50 & 26 \\ 13 & 16 \\ 195 & 159\end{array}$

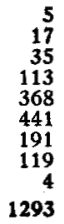


of the data shows that decreasing temperatures occurred in the 0 to $2-\mathrm{m}$. layer 27 per cent of the time and actual superadiabatic conditions 20.4 per cent. A decrease in temperature with height in these shallow layers is practically equal to an unstable condition, although by definition an unstable condition would have a temperature decrease in excess of $0.02^{\circ} \mathrm{C}$ in the 0 to $2-\mathrm{m}$. layer. Temperature decreases equal to $0.01^{\circ} \mathrm{C}$ per metre are actually neutral, neither stable nor unstable, but have been tabulated with the unstable conditions. Inversions with lapse rates less than $-0.5^{\circ} \mathrm{C}$ occurred 63.4 per cent and 41.3 per cent of the time in the 0 to $2-\mathrm{m}$. and 2 to $5-\mathrm{m}$. layers, respectively.

Table 2. Percentage of time during which temperature decreases occurred in the surface to 2-metre level and the 2 to 5-metre level. Hourly average data for the period 1 January to 28 February 1954, Eielson Air Force Base, Alaska.

\begin{tabular}{|c|c|c|c|c|c|c|c|}
\hline \multirow[b]{2}{*}{ Levels. } & \multicolumn{7}{|c|}{2 metre temperature ${ }^{\circ} \mathrm{C}$} \\
\hline & $\begin{array}{l}\text { Below } \\
-40.0\end{array}$ & $\begin{array}{l}-40.0 \\
t 0 \\
-35.1\end{array}$ & $\begin{array}{r}-35.0 \\
\text { to } \\
-30.1\end{array}$ & $\begin{array}{r}-30.0 \\
t o \\
-25.1\end{array}$ & $\begin{array}{r}-25.0 \\
\quad t o \\
-20.1\end{array}$ & $\begin{array}{r}-20.0 \\
t 0 \\
-15.1\end{array}$ & $\begin{array}{r}-15.0 \\
t 0 \\
-10.1\end{array}$ \\
\hline Surface to $2 \mathrm{~m}$. & 4.8 & 15.2 & 26.2 & 23.6 & 26.0 & 48.0 & 35.0 \\
\hline $2 \mathrm{~m}$. to $5 \mathrm{~m}$. & 50.0 & 30.0 & 23.3 & 16.8 & 14.4 & 32.3 & 26.4 \\
\hline
\end{tabular}

The distribution of the decreasing temperature conditions with respect to 2-m. ambient temperature is shown in Table 2. The unstable conditions at temperatures below $-30^{\circ} \mathrm{C}$ probably resulted largely from the "greenhouse" effect of ice fog, since at these temperatures the fog was almost always present. Lapse conditions at warmer temperatures would be expected to be due principally to insolational heating, although the warm-layer radiation type would also occur in this warmer temperature range. From Table 2 it appears that at the lower temperatures the unstable conditions were more often found above the surface layer, in the 2 to $5-\mathrm{m}$. layer, whereas at temperatures between $-30^{\circ} \mathrm{C}$ and $-10^{\circ} \mathrm{C}$ an unstable 0 to $2-\mathrm{m}$. layer was more general. This latter situation can doubtless be attributed to the insolation type of instability usually found in the warmer temperature range. Although there does appear to be an indication of less frequent unstable conditions in the 0 to $2-\mathrm{m}$. layer at colder temperatures, a single year's data are not sufficient basis for any firm conclusions. Data from other arctic areas and collected over a number of winter seasons are needed to clarify these stability relationships.

The frequencies of unstable temperature conditions through successively thicker strata to the top of the tower are shown in Table 3. This tabulation differs slightly from Table 1 for the 2 to $5-\mathrm{m}$. layer by excluding positive

Table 3. Frequency of occurrence of unstable temperature conditions $\left(\triangle T / \triangle H \leq 0.01^{\circ}\right.$

C. $/ \mathrm{m}$.) through several layers. Hourly average tower data, 1 January to 28 February 1954, Eielson Air Force Base, Alaska.

$\begin{array}{lc}\text { Levels } & \text { \% Unstable } \\ \text { Surface to } 2 \mathrm{~m} . & 27 \\ 2 \mathrm{~m} \text {. to } 5 \mathrm{~m} . & 23 \\ 2 \mathrm{~m} . \text { to } 10 \mathrm{~m} . & 11 \\ 2 \mathrm{~m} . \text { to } 20 \mathrm{~m} \text {. } & 5 \\ 2 \mathrm{~m} \text {. to } 29 \mathrm{~m} . & 10\end{array}$

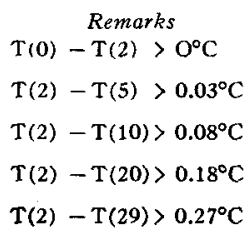


temperature differences less than $0.03^{\circ} \mathrm{C}$, which being less than the dry adiabatic condition, are stable conditions. The Table 3 data indicate that unstable lapse rates are most frequent in the surface to $2-\mathrm{m}$. layer and least frequent in the layer between $2 \mathrm{~m}$. and $20 \mathrm{~m}$.

A superadiabatic or unstable atmospheric condition requires a continuous source of energy to perpetuate itself. In the present instances the source of energy was apparently incoming radiation absorbed by the snow surface and then transferred, or radiated, to the lower levels of the atmosphere by conduction and absorption. It seems most likely that conduction was the principal mechanism except in the presence of fog aerosols, in which case the particles probably played a significant role in the absorption of long wave radiation from the surface. The albedo or reflectivity of the snow surface is undoubtedly a factor which must be considered in these problems of radiation. In the present instances the snow surface was generally not fresh but was often dirty and crusty, particularly during February. This surface condition produces a lower albedo value and a surface more conducive to surface heating than fresh snow.

Of the unstable surface conditions discussed, the insolation type is doubtless the most important in the arctic climatological regime. Under such conditions the snow can disappear rapidly even though the temperature may never approach the melting point. Since the unstable conditions permit the rapid transport of water vapour out of the surface layers, this provides a mechanism quite favourable for the ablation of the snow cover. The turbulent condition generated by a warm air mass aloft would have to be frequent to be an important feature of the arctic climate, but even with limited occurrences it may be of value in understanding some micrometeorological processes in both arctic and temperate regions. The observation of instability within an ice fog layer helps to explain the phenomenon and must be taken into consideration when any amelioration of ice fog situations are proposed. However, ice fog is a product of human habitations under special arctic conditions, and the lapse rates associated with it are restricted to urban areas.

The assistance of the U.S. Air Force at Eielson AFB and of the Stanford Research Institute Ice Fog Project personnel is gratefully acknowledged, in particular that of Gordon B. Bell, who supplied the figures and the data tabulations given here.

\section{References}

Fleagle, R. G., W. H. Parrott, and M. L. Barad. 1952. "Theory and effects of vertical temperature distribution in turbid air". J. Meteorol. Vol. 9, Pp. 53-60.

Thornthwaite, C. W. 1949. 'Micrometeorology of the surface layer of the atmosphere'. Interim report No. 6 and No. 7, John Hopkins Univ. Lab. of Climatology.

Wiggins, E. J., E. Robinson, W. C. Thuman, G. B. Bell, and G. A. St. John. 1954. 'An investigation of the ice fog phenomenon in the Alaskan area'. Report No. 21, Stanford Res. Inst., Project CU-473. 